\title{
EVALUACIÓN DE LA HIDRÓLISIS ENZIMÁTICA DE PLUMAS DE POLLO PARA LA OBTENCIÓN DE QUERATINA
}

\author{
Lilibeth Viloria Sierra ${ }^{1}$, María Paula Azabache Zarta², Rafael Nikolay Agudelo Valencia ${ }^{3}$, Javier \\ Adolfo Hernández Fernández ${ }^{4}$
}

\begin{abstract}
${ }^{1}$ Estudiante de ingeniería Ambiental, lilibeth-vilorias@unilibre.edu.co, ${ }^{2}$ Estudiante de ingeniería Ambiental, mariap-azabachez@unilibre.edu.co, ${ }^{3}$ M. Sc., Docente de planta, rafaeln.agudelov@unilibre.edu.co, ${ }^{4} \mathrm{Ph}$. Dc., Docente de planta, Universidad Jorge Tadeo Lozano, Javier.hernandez@utadeo.edu.co. 1, 2,3 Universidad Libre de Colombia
\end{abstract}

\section{RESUMEN}

Esta investigación evaluó la hidrólisis enzimática de plumas de pollo para la obtención de queratina hidrolizada como alternativa de valorización de este desecho generado por la industria avícola. La hidrólisis se realizó con la enzima Genencor® Tan G plus, utilizando un diseño experimental de tipo central compuesto, seleccionando como factores el $\mathrm{pH}(8 \mathrm{a} 9)$, la temperatura $\left(20^{\circ} \mathrm{C} \mathrm{a} 30^{\circ} \mathrm{C}\right)$ y la dosis de enzima $(0.03 \mathrm{~g} \mathrm{a} 0.05 \mathrm{~g})$, y como respuesta la concentración de proteína en el extracto empleando para ello el método de Bradford y electroforesis en gel SDS-PAGE para conocer la pureza. Los resultados se estudiaron por un análisis de varianza y por la metodología superficie de respuesta obteniendo a un $\mathrm{pH}$ de 8 , dosis de enzima de $0.03 \mathrm{~g}$ y temperatura de $25^{\circ} \mathrm{C}$, una concentración máxima de $2.106 \mathrm{mg} / \mathrm{mL}$ siendo el $\mathrm{pH}$ y la temperatura $\left({ }^{\circ} \mathrm{C}\right)$ los factores significativos de la hidrólisis.

Palabras clave: Plumas, Hidrólisis enzimática, Queratina, Proteína, Valorización.

Recibido: 24 de Abril de 2019. Aceptado: 19 de Julio de 2019.

Received: April 24, 2019. Accepted: July 19, 2019.

\section{EVALUATION OF ENZYMATIC HYDROLYSIS OF POULTRY FEATHERS FOR OBTAINING KERATIN}

\section{ABSTRACT}

This research evaluated the enzymatic hydrolysis of chicken feathers to obtain hydrolyzed energy as an alternative to valorize this design generated by the poultry industry. The hydrolysis was performed with the enzyme Genencor ${ }^{\circledast}$ Tan $G$ plus, using an experimental design of central compound type, selecting as factors the $\mathrm{pH}\left(8\right.$ to 9), the temperature $\left(20^{\circ} \mathrm{C}\right.$ to $30^{\circ} \mathrm{C}$ ) and the enzyme dose $(0.03 \mathrm{~g}$ to $0.05 \mathrm{~g})$, and in response to the concentration of the protein in the extract using the Bradford method and SDS-PAGE gel electrophoresis to determine the purity. The results are studied by means of an analysis of the variance and the methodology of the response surface obtaining a $\mathrm{pH}$ of 8 , an enzyme dose of $0.03 \mathrm{~g}$ and a temperature of $25^{\circ} \mathrm{C}$, a maximum concentration of $2.106 \mathrm{mg} / \mathrm{mL}$ being the $\mathrm{pH}$ and temperature $\left({ }^{\circ} \mathrm{C}\right)$ The significant factors of hydrolysis.

Keywords: Feathers, Enzymatic hydrolysis, Keratin, Protein, Valorization.

Cómo citar este artículo: L. Viloria, M. Azabache, Y. Agudelo, J Hernández. "Evaluación de la hidrólisis enzimática de plumas de pollo para la obtención de queratina", Revista Politécnica, vol. 15, no.30 pp.17-20, 2019. DOI: 10.33571/rpolitec.v15n30a2 


\section{INTRODUCCIÓN}

La industria avícola genera distintos tipos de desechos tales como sangre, huesos, piel, vísceras y plumas. Estas últimas, representan aproximadamente el $8 \%$ del peso vivo del ave de corral [1], a pesar de la disponibilidad y de los bajos costos de las plumas, no existen productos principales o aplicaciones a gran escala derivadas de estas [2]. La disponibilidad de plumas se puede fundamentar en que anualmente de 200 pollos se pueden generar $30 \mathrm{~kg}$ de estas [3].

La industria avícola está en constante crecimiento y los mayores productores del mundo son EEUU, Brasil, China y la Unión Europea que tiene una producción anual aproximadamente de 11 millones de toneladas de carne de pollo [1]. El sector avícola también ocupa un lugar importante en la producción colombiana, contribuyendo un porcentaje significativo al PIB Nacional, con una tasa de crecimiento del $6.6 \%$ del PIB para el sector pecuario en el tercer trimestre de 2018 [4]. Los sistemas de producción avícola también han conllevado al deterioro ambiental, dando lugar a la emisión de altas concentraciones de gases de efecto invernadero como óxidos de nitrógeno, fósforo y azufre [5].

En la búsqueda de alternativas para el aprovechamiento de residuos del sector avícola, surge la cuestión con relación a la valorización de las plumas de pollo, con lo cual se espera lograr la disminución de emisiones como resultado de la incineración de este residuo [6], y de igual forma prevenir la ejecución de malas prácticas de disposición final, tales como, la descarga de plumas a través de las tuberías de desagüe generando taponamientos que pueden dar lugar a reacciones químicas con productos sulfurosos de olores desagradables y posiblemente peligrosos para la salud [7].

Una alternativa para el aprovechamiento de plumas de pollo es la obtención de queratina hidrolizada, este proceso se ha realizado con el uso de Queratinasas obtenidas a partir de Bacillus Spp, como resultado se determinó que es posible la hidrólisis enzimática de harina de plumas de pollo utilizando Bacillus subtilis como productor de proteasa [3]. La queratina hidrolizada ha sido también obtenida a partir de hidrolasas, con lo cual se satisface el interés en aumento del uso de materiales renovables y sostenibles [2].
Por otra parte y teniendo presente el alto contenido proteico en los productos derivados de animales como por ejemplo plumas, pelo, pezuñas y uñas; se hace claro que existe el potencial de aprovechamiento de ellos con fines nutricionales o como fertilizante [8], y para la elaboración de compost debido a su contribución en el desarrollo de los microorganismos que enriquecen el suelo en nitrógeno y fósforo [9]. Así mismo, la queratina siendo un componente rico en azufre puede ser utilizada en la fabricación de cremas para solucionar problemas capilares [10], a su vez las aplicaciones de la queratina soluble a nivel cosmético y farmacéutico son amplias y variadas, de igual modo han surgido otros usos de la queratina de plumas como componente de varias clases de compuestos y en tejidos biodegradables [11].

Con respecto a la queratina, es preciso señalar a las plumas como un residuo sólido que contiene $90 \%$ de esta proteína, que tiene como función la protección y el soporte de las capas externas de la epidermis [3], la queratina presenta alta resistencia a la degradación natural. Adicionalmente en los procesos de sacrificio las plumas se contaminan con desechos tales como sangre, grasa, microorganismos y agua, hecho que puede causar una mayor resistencia a la degradación natural. Debido a lo anterior, se considera la hidrólisis como una alternativa, en la gestión de los residuos de plumas, este proceso se constituye como una reacción de descomposición de sustancias por acción de las moléculas de agua generando compuestos más solubles en la misma, es lento y requiere de parámetros idóneos de temperatura, velocidad de agitación (rpm) y $\mathrm{pH}$ del medio reactivo. La hidrólisis se realiza mediante el uso de catalizadores que aceleran la reacción, de los cuales existen tres principales tipos, catalizadores ácidos, básicos y enzimas [12]. Los procesos de hidrólisis química generalmente implican el uso de sustancias tales como sulfuro de sodio y borohidruro de sodio [13], agresivas con el ambiente que a su vez pueden generar afectaciones a la salud de las personas [14, 15] , por este motivo se prefirió por llevar a cabo un proceso hidrolítico.

En este artículo se presentan los resultados del proceso de hidrólisis enzimática de plumas de pollo para el cual se empleó la enzima Genencor® Tan $\mathrm{G}$ plus (proteasa) a distintos $\mathrm{pH}$ de reacción (8.0, 8.5 y 9.0), temperatura $\left(20^{\circ} \mathrm{C}, 25^{\circ} \mathrm{C}\right.$ y $\left.30^{\circ} \mathrm{C}\right)$ y dosis de enzima $(0.03,0.04,0.05$. De acuerdo a fabricante, la enzima Genencor ${ }^{\circledR}$ Tan $G$ plus es útil 
a pH dentro de un rango de 7.0 hasta 11.0 (con un $\mathrm{pH}$ óptimo de alrededor de 8.6), también es efectiva en el rango de temperatura de $25^{\circ} \mathrm{C}$ hasta $30^{\circ} \mathrm{C}$, La enzima es derivada de una cepa modificada genéticamente de Bacillus subtilis y según su fabricante resulta útil en los procesos de preparación de cueros[16]. Para la aplicación descrita en este trabajo se desconoce el rendimiento óptimo (en $\mathrm{pH}$ y temperatura ${ }^{\circ} \mathrm{C}$ ) de la enzima Genencor® Tan G plus, por tanto para disminuir los errores de los ensayos se establecieron los valores de los niveles del diseño experimental muy cerca de los límites previamente estipulados por el fabricante de la enzima.

Las proteasas son enzimas que catalizan la hidrólisis de los enlaces peptídicos de las proteínas, presentan la capacidad de romper enlaces peptídicos específicos, dependiendo de la secuencia de aminoácidos de la proteína, o pueden reducir un péptido completo a aminoácidos. La ecuación 1, que aparece a continuación resume el mecanismo catalítico de una enzima proteasa sobre un sustrato proteico.

$$
E+S \stackrel{K_{-1} K_{1}}{\longrightarrow} E S \stackrel{K_{2}}{\rightarrow} E P+H-P^{\prime} \stackrel{H_{2} O, K_{3}}{\longrightarrow} E+P-O H+H-P^{\prime}
$$

E: Enzima, S: Sustrato, $P, P^{\prime}$ péptidos resultantes, $K_{x}$ coeficiente cinético de reacción [17].

\section{MATERIALES Y MÉTODO}

Las plumas para la realización de ensayos fueron proporcionadas por el consorcio avícola Santa Helena en Bogotá y utilizadas en su totalidad (raquis y barbillas). Las plumas fueron lavadas con agua y alcohol, posteriormente secadas en horno a $40^{\circ} \mathrm{C}$ durante 24 horas, después de ello fueron molidas en un molino IKA-Universal Mühle M20, el producto obtenido en la molienda fue tamizado en un tamiz de malla de 75 Micras y utilizado en su totalidad para realizar la hidrólisis. El procedimiento seguido en los ensayos se describe en la figura 1.

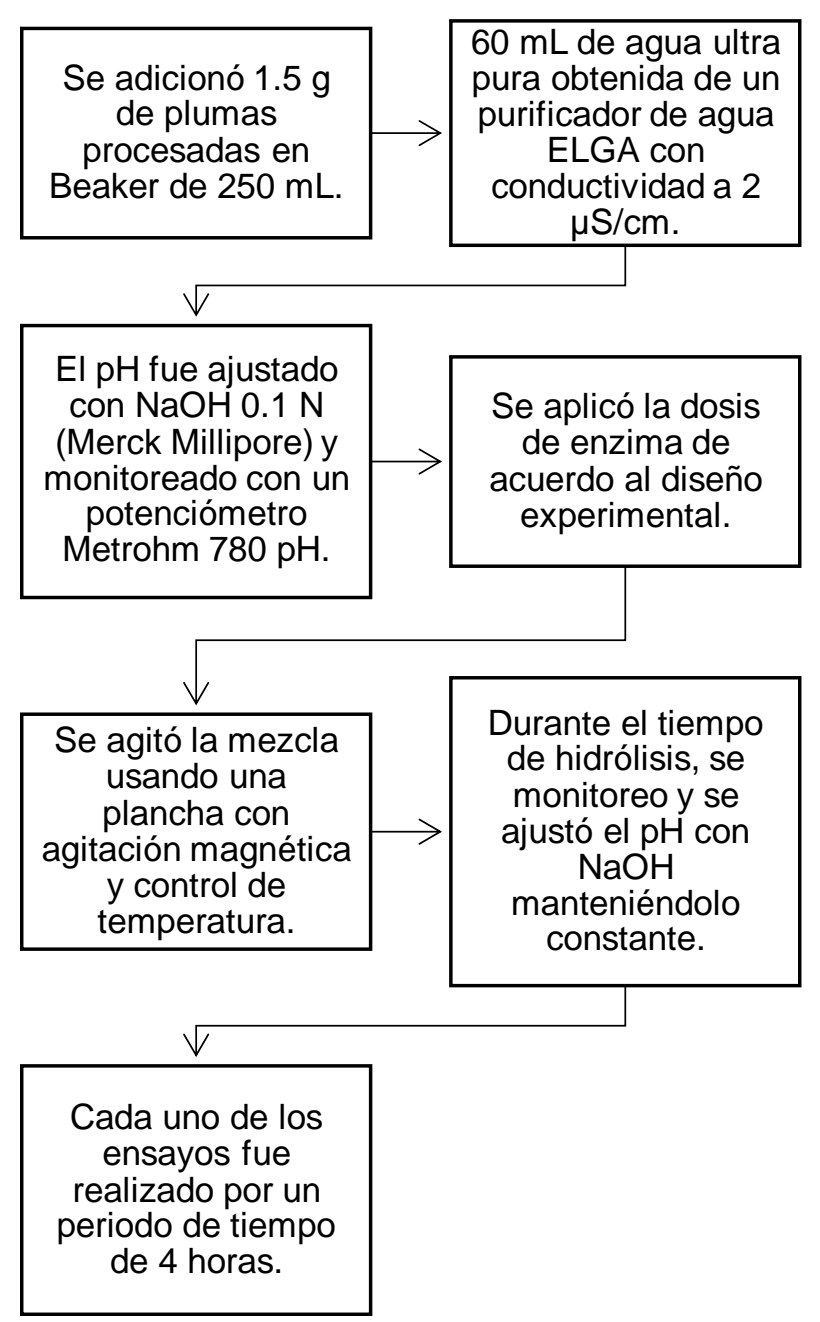

Fig.1. Proceso para realizar ensayos de hidrólisis.

La concentración de proteína $[\mathrm{mg} / \mathrm{mL}]$ hidrolizada fue determinada por el Método de Bradford [18] , para la realización de la curva de calibración y posterior cuantificación de proteína se empleó albumina de suero bovino (BSA) a diferentes diluciones, la curva patrón se realizó para una longitud de onda de $595 \mathrm{~nm}$ y el coeficiente de correlación $\left(\mathrm{R}^{2}\right)$ obtenido alcanzó un valor de 0.99841 . Es preciso señalar que el método de Bradford permite determinar la presencia de proteína en las muestras, y teniendo en cuenta que el $90 \%$ del contenido de las plumas corresponde a queratina [12], es aceptable indicar que la proteína cuantificada por el método de Bradford corresponde a queratina hidrolizada.

La identificación de proteína hidrolizada obtenida en cada uno de los ensayos fue llevada a cabo por la técnica de electroforesis en gel de poliacrilamida dodecilsulfato de sodio (SDS-PAGE), esta técnica permite realizar la separación e identificación de proteína [18]. Se llevó a cabo en la cámara de 
electroforesis Mini-PROTEAN ${ }^{\circledR}$ Tetra cell, la diferencia de potencial aplicado para la corrida electroforética fue de 25 Voltios y el tiempo empleado fue de 2.5 horas, la tinción de las proteínas fue realizada con Azul brillante Coomasie R-250 y la decoloración se efectuó con ácido acético y metanol diluido en agua destilada.

El diseño experimental realizado fue factorial del tipo central compuesto con tres réplicas del punto central [19], en el cual se estudió el efecto de tres factores y dos niveles de cada uno, los factores fueron el pH (8 a 9), la temperatura $\left(20^{\circ} \mathrm{C}\right.$ a 30 ${ }^{\circ} \mathrm{C}$ ), y la dosis de enzima (0.03 g a $\left.0.05 \mathrm{~g}\right)$. La variable de respuesta seleccionada fue la concentración de proteína $[\mathrm{mg} / \mathrm{mL}]$ en el extracto y el número de ensayos realizado fue igual a 17 , el análisis de los resultados experimentales fue realizado con el software Design-Expert bajo licencia, obteniendo un modelo de segundo orden que se analizó mediante un gráfico de Pareto, un análisis de varianza (por sus siglas en inglés ANOVA), y una gráfica de superficie de respuesta a fin de fijar interacciones entre las variables y conocer la mejor combinación para la obtención de queratina hidrolizada [19].

\section{RESULTADOS}

La influencia de cada una de las variables sobre la respuesta del sistema analizado, se puede observar en el diagrama de Pareto el cual fue realizado en el programa Minitab bajo licencia y que aparece en la figura 2

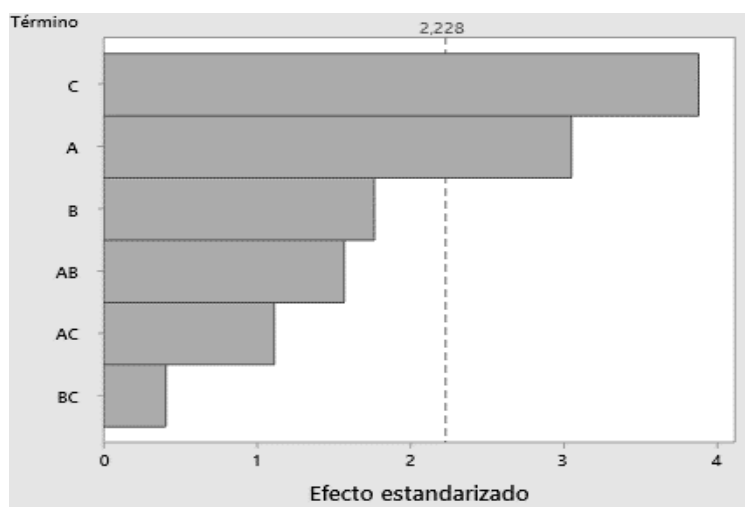

Fig. 2. Diagrama Pareto de efectos estandarizados en la obtención de queratina hidrolizada, factores: $\mathrm{A}: \mathrm{pH}, \mathrm{B}$ : Dosis de enzima, y C: temperatura.

En la gráfica se observa que la temperatura y el pH son las variables que afectan en mayor medida la respuesta del sistema, seguido por la variable dosis de enzima y la interacción de esta con el pH, de acuerdo a lo anterior, la superficie de respuesta para la determinación de la máxima concentración de queratina hidrolizada, se construirá exceptuando los efectos $A^{2}, B^{2}$ y $C^{2}$.

Los resultados de concentración de proteína obtenida en los ensayos por medio de la metodología superficie de respuesta (MSR) son presentados en figura 3.

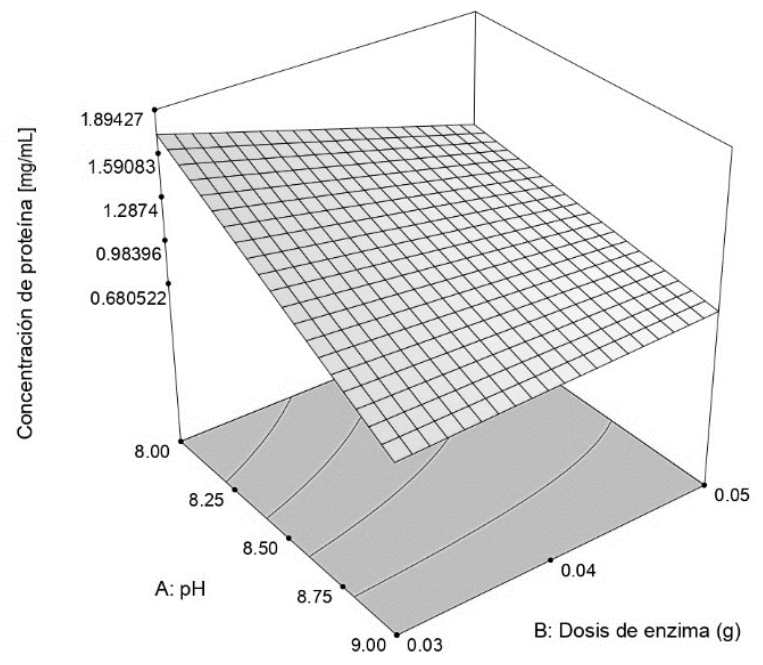

Fig. 3. Superficie de respuesta, factores A: $\mathrm{pH}, \mathrm{B}$ : Dosis de enzima, temperatura $25^{\circ} \mathrm{C}$. variable de respuesta concentración de proteína $[\mathrm{mg} / \mathrm{ml}]$.

En la figura se observa que la concentración de queratina hidrolizada tiende a ser mayor para los ensayos realizados a $\mathrm{pH}$ levemente alcalino $(\mathrm{pH} 8)$ y bajas dosis de enzima Genencor $\AA$ Tan $G$ plus, también se aprecia que a pH 9 la dosis de enzima no afecta de manera significativa la cantidad de proteína hidrolizada obtenida, por otra parte, la máxima concentración de proteína alcanzó un valor de $2.106 \mathrm{mg} / \mathrm{mL}$ a una dosis de enzima Genencor® Tan $\mathrm{G}$ de $0.03 \mathrm{~g}, \mathrm{pH} 8.0$ y temperatura de $25^{\circ} \mathrm{C}$

La figura 4, representa la superficie de respuesta para la concentración de proteína hidrolizada contra el $\mathrm{pH}$ y la temperatura a dosis de enzima constante de $0.03 \mathrm{~g}$. 


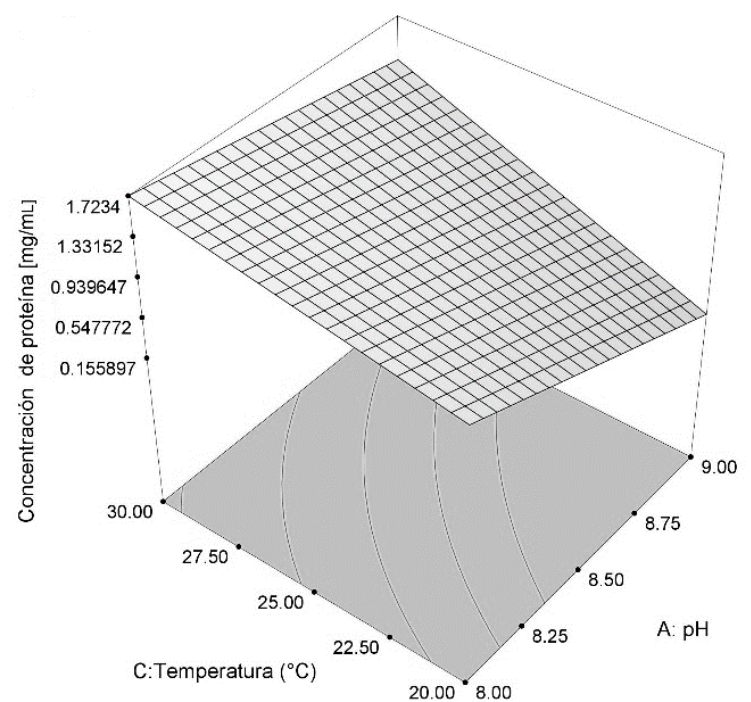

Fig. 4. Superficie de respuesta, factores $\mathrm{A}: \mathrm{pH}, \mathrm{B}$ : C: Temperatura $\left({ }^{\circ} \mathrm{C}\right)$, Dosis de enzima $0.03 \mathrm{~g}$. variable de respuesta concentración de proteína $[\mathrm{mg} / \mathrm{mL}]$.

Se aprecia que a medida que el pH de la solución aumenta la concentración de proteína disminuye, por su parte al aumentar la temperatura aumenta la cantidad de proteína obtenida, este efecto se aprecia en mayor proporción a pH 9. El resultado del análisis de las dos superficies de respuesta permite confirmar lo expuesto en el gráfico de Pareto y es que, para el rango de las variables analizadas, la dosis de enzima es la variable que da lugar a las menores variaciones en la cantidad de producto obtenido, lo que desde el punto de vista económico representa una ventaja para el proceso, pues puede ser empleada la dosis más baja de enzima para obtener la máxima cantidad de producto, variando dos variables relativamente simples de controlar en un proceso, como son el $\mathrm{pH}$ y la temperatura.

La tabla 1. Corresponde al análisis de varianza de los resultados experimentales, a partir del ANOVA se puede concluir que las variables o factores analizados dan lugar a cambios en la variable de respuesta, que para el presente caso fue la concentración de proteína hidrolizada en la solución obtenida.

A partir de los datos de la tabla, se confirma que las variables más significativas o de mayor peso para el proceso de hidrólisis enzimática son el pH y la temperatura, seguido por la dosis de enzima aplicada dentro de los valores de los niveles seleccionados de cada variable o factor analizado.

Tabla. 1. Análisis de varianza (ANOVA) a partir de los resultados de Bradford de cada muestra.

\begin{tabular}{|c|c|c|c|c|c|}
\hline $\begin{array}{l}\text { Fuente } \\
\text { variación }\end{array}$ & $\begin{array}{c}\text { de Suma de } \\
\text { Cuadrados }\end{array}$ & $\begin{array}{l}\text { Grados de } \\
\text { libertad }\end{array}$ & $\begin{array}{l}\text { Cuadrados } \\
\text { medios }\end{array}$ & Valor F & Prob $>F$ \\
\hline \multirow{4}{*}{$\begin{array}{l}\text { Modelo } \\
\text { A: pH } \\
\text { B: Dosis de } \\
\text { enzima } \\
\text { C: Temperatura } \\
{ }^{\circ} \mathrm{C} \\
\mathrm{A}^{2}\end{array}$} & $\begin{array}{l}3.19 \\
1.13\end{array}$ & $\begin{array}{l}9 \\
1\end{array}$ & $\begin{array}{l}0.35 \\
1.13\end{array}$ & $\begin{array}{l}3.35 \\
10.70\end{array}$ & $\begin{array}{l}0.0625 \\
0.0137\end{array}$ \\
\hline & 0.27 & 1 & 0.27 & 2.55 & 0.1541 \\
\hline & 1.33 & 1 & 1.33 & 12.57 & 0.0094 \\
\hline & $\begin{array}{l}0.039 \\
0.074\end{array}$ & $\begin{array}{l}1 \\
1\end{array}$ & $\begin{array}{l}0.039 \\
0.074\end{array}$ & $\begin{array}{l}0.36 \\
0.70\end{array}$ & $\begin{array}{l}0.5648 \\
0.4291\end{array}$ \\
\hline $\mathrm{C}^{2}$ & $2.179 \mathrm{E}-003$ & 1 & $2.179 \mathrm{E}-003$ & 0.021 & 0.8899 \\
\hline$A B$ & 0.21 & 1 & 0.21 & 2.01 & 0.1989 \\
\hline AC & 0.11 & 1 & 0.11 & 1.02 & 0.3468 \\
\hline BC & 0.014 & 1 & 0.014 & 0.13 & 0.7242 \\
\hline Residual & 0.74 & 7 & 0.111 & & \\
\hline Falta de Ajuste & 0.74 & 3 & 0.25 & 266.97 & $<0.0001$ \\
\hline Error Puro & 3.680E-003 & 4 & 9.200 E-004 & & \\
\hline Total, corregido & 3.93 & 16 & & & \\
\hline
\end{tabular}




\subsection{Interacción de los factores significativos sobre la variable de respuesta}

El análisis de interacción de las variables o factores permite analizar el efecto de estas sobre la variable de respuesta, la figura 5 corresponde al gráfico de interacción de los factores significativos.

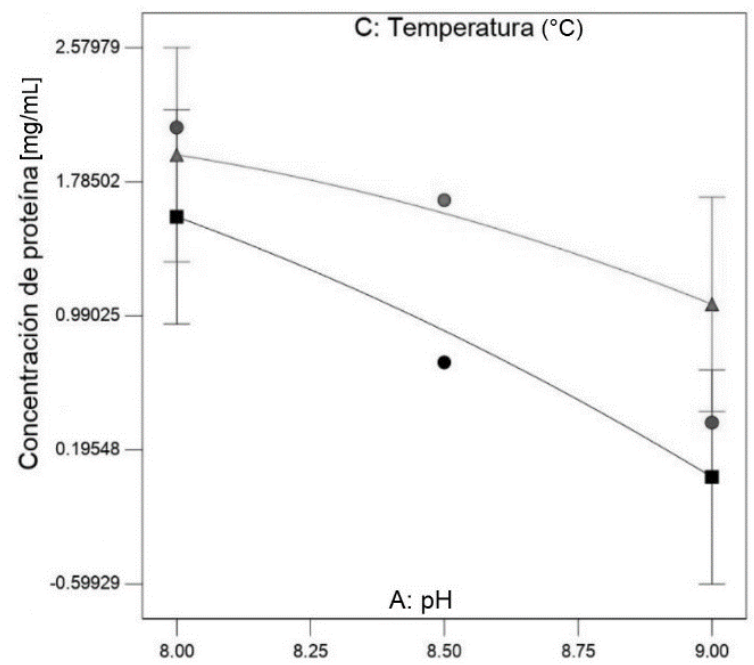

Fig. 5. Efecto de $\mathrm{A}: \mathrm{pH}$ y C: Temperatura ${ }^{\circ} \mathrm{C}$ sobre la concentración de proteína hidrolizada $[\mathrm{mg} / \mathrm{mL}]$.

En la figura 5 se observa que los factores significativos para el proceso $\mathrm{A}$ : $\mathrm{pH}$ y $\mathrm{C}$ : Temperatura $\left({ }^{\circ} \mathrm{C}\right)$ intervienen en la respuesta concentración de proteína hidrolizada. Para temperaturas entre $20^{\circ} \mathrm{C}$ hasta $30^{\circ} \mathrm{C} \mathrm{y} \mathrm{pH} 8.0$ se tiene la mejor condición de hidrólisis enzimática obteniendo mayor cantidad de proteína hidrolizada.

\subsection{Ecuación final en términos de factores reales:}

A partir de los datos experimentales se logró determinar la ecuación (2) con un coeficiente de correlación $R^{2}$ de 0.8074 , correspondiente a la superficie de respuesta presentada en las figuras 3 y 4 .

$$
\begin{aligned}
& \text { Concentración de proteína } \\
& \quad=1.10-0.38 \times A-0.18 \times B \\
& \quad+0.41 \times C+0.23 \times A \times B \\
& \quad+0.16 \times A \times C+0.060 \times B \times C
\end{aligned}
$$

$\mathrm{A}=\mathrm{pH} ; \mathrm{B}=$ Dosis de enzima; $\mathrm{C}=$ Temperatura.

A partir de la ecuación 1 , se determinan los valores de las variables que permiten alcanzar la mayor concentración de proteína hidrolizada en el medio de reacción, para esto fue empleado el software Design-Expert bajo licencia. El resultado de la optimización señala que a pH 8.0 y $25^{\circ} \mathrm{C}$ de temperatura, para una dosis de $0.03 \mathrm{~g}$ de enzima se alcanza la máxima concentración de queratina hidrolizada en el producto.

\subsection{Determinación del porcentaje de masa}

El porcentaje de obtención de proteína hidrolizada en cada uno de los ensayos fue determinado a partir de la ecuación 3 , la expresión matemática permite establecer dicho porcentaje a partir de la concentración de proteína hidrolizada obtenida en la metodología de Bradford, con base en el sustrato de plumas y el volumen de la mezcla reactiva en cada ensayo.

$$
\begin{gathered}
\% \text { de masa }= \\
\frac{\text { Concentración }\left(\frac{\mathrm{mg}}{\mathrm{ml}}\right) * \text { Volumen de la solución }(\mathrm{ml})}{\text { Sustrato de plumas }(\mathrm{g})}
\end{gathered}
$$

Aplicando la ecuación anterior se determinó que el mayor porcentaje de masa obtenida para la totalidad de los experimentos realizados alcanzó un valor del $8.42 \%$, con una concentración de plumas de $0.025 \mathrm{~g} / \mathrm{m} \mathrm{L}$, una dosis de enzima de $0.03 \mathrm{~g}$ y a una temperatura de $25^{\circ} \mathrm{C}$.

\subsection{Resultados de electroforesis en gel de poliacrilamida dodecilsulfato de sodio (PAGE- SDS)}

La electroforesis fue realizada a las muestras con mayor concentración de proteína de acuerdo a los resultados obtenidos en la metodología de Bradford, en estas se pudo observar la tinción por la presencia de proteínas hidrolizadas resultantes del tratamiento dado en cada ensayo. En la electroforesis se tomó como referencia el marcador de peso de proteínas Opti-Protein XL Marker $(\sim 10 \mathrm{kDa}-\sim 245 \mathrm{kDa})$ [20]. Se pudo encontrar bandas correspondientes a los pesos moleculares de $35 \mathrm{kDa}, 48 \mathrm{kDa}$ y $50 \mathrm{kDa}$, las dos últimas bandas mencionados se encuentran entre el rango de peso molecular de la queratina, el cual varía entre 40 y $70 \mathrm{kDa}[13]$.

\section{DISCUSIÓN}

De acuerdo a los resultados obtenidos en el diagrama de Pareto y el ANOVA, la temperatura y el pH son factores significativos para la obtención de la proteína hidrolizada (queratina) en presencia 
de la enzima proteolítica Genencor® Tan G plus; se observó que los cambios de estas dos variables dan lugar a considerables variaciones de la hidrólisis enzimática, resultados que concuerdan con los obtenidos por E. Gaviria Acosta, R. Benítez y L. Lenis [21], en este estudio se determinó que los cambios en el pH (siendo 7.2 el óptimo) del medio de reacción dan lugar al cambio estructural de la proteína, por otra parte, el incremento de la dosis de enzima no da lugar a cambios bruscos en el grado de hidrólisis y por consiguiente en la cantidad de proteína encontrada.

Por tanto se puede decir que el valor obtenido de proteína en el presente estudio (\% de masa= $8.42 \%$, con una concentración de plumas de 0.025 $\mathrm{g} / \mathrm{mL}$ y una dosis de enzima de $0.03 \mathrm{~g}$ ) es comparable o similar con la cantidad de proteína obtenida en la investigación realizada por M. B. Valencia Andrade [12], en la que se obtuvo un $2.9 \%$ de queratina hidrolizada con $0.04 \mathrm{~g} / \mathrm{mL}$ de plumas y $0.075 \mathrm{~g}$ de enzima, en este trabajo fueron realizadas pruebas previas con Sulfuro de Sodio y Metabisulfito de sodio a fin de realizar una hidrólisis preliminar de la queratina y posteriormente llevar a cabo hidrólisis enzimática de plumas.

De igual manera, en la investigación realizada por G. Machuca Loja, B. Madrid Celi , D. Sanmartin Galvan \& J. Pérez Rodríguez [3] se alcanzó un $65.75 \%$ de queratina hidrolizada con una dosis de sustrato de plumas de $0.018 \mathrm{~g} / \mathrm{mL}$ y $3 \mathrm{~g}$ de enzima, en este caso la relación sustrato de plumas-enzima fue aquella que permitió alcanzar el mayor porcentaje de queratina hidrolizada.

La electroforesis es fundamental en la descripción de proteínas esto coincide con R. Benítez, A. Ibarz y J. Pagan [22] donde afirman que un parámetro importante para la hidrólisis de proteína es la distribución del peso molecular de los péptidos en los hidrolizados, por lo cual se emplean técnicas como SDS-PAGE.

\section{CONCLUSIONES}

Con base en los resultados obtenidos se determina que el mayor porcentaje de proteína hidrolizada conseguida alcanzó un valor de $2.106 \mathrm{mg} / \mathrm{mL}$, equivalente al $8.42 \%$ de la masa inicial de sustrato (plumas), este valor se consiguió para $\mathrm{pH} 8$, dosis de enzima $0.03 \mathrm{~g}$ y $25^{\circ} \mathrm{C}$ de temperatura. A partir del diagrama de Pareto y el diseño experimental analizado por MSR y el ANOVA, se estableció que el $\mathrm{pH}$ y la temperatura son los factores que presentan la mayor influencia sobre el rendimiento de queratina hidrolizada obtenida, seguido por la variable dosis de enzima y la interacción de esta con el $\mathrm{pH}$, de igual manera, que la reacción de hidrólisis enzimática se favorece para $\mathrm{pH}$ ligeramente alcalino. La hidrólisis enzimática puede permitir la valorización de los residuos de plumas de la industria avícola, esta metodología se caracteriza por no ser agresiva con el medio ambiente, por tanto en casos donde sea utilizada se evita la aparición de problemas adicionales a los existentes por mala disposición de plumas.

La electroforesis en gel SDS-PAGE, es una técnica efectiva para la determinación y caracterización del peso molecular de queratina hidrolizada pero a su vez, es una técnica muy sensible donde es esencial ser exactos en la preparación de los geles, el tiempo de corrida y en la pureza de los reactivos.

El beneficio ambiental generado se fundamenta en el valor agregado de las plumas de la industria avícola al realizar hidrólisis enzimática, ya que el producto a obtener es queratina muy utilizada en la industria cosmética; influyendo directamente en la disminución de las plumas como desechos, como residuo dispuesto para la quema o alimento para animales, evitando de esta manera las afectaciones al medio ambiente y a la salud de la población.

\section{AGRADECIMIENTOS}

A la empresa MerQuiand S.A.S por el suministro de la enzima Genencor ${ }^{\circledR}$ Tan $G$ plus utilizada en cada uno de los ensayos, al consorcio avícola Santa Helena en Bogotá por el suministro de las plumas, a María del Pilar Rodríguez por la ayuda en el desarrollo de cada uno de los laboratorios, y a Yerson Amezquita Sayo por su colaboración en el pre tratamiento de las plumas.

\section{REFERENCIAS BIBLIOGRÁFICAS}

[1] A. Brandelli , L. Sala y S. Juliano Kalil, .Microbial enzymes for bioconversion of poultry waste into added-value products, Food Research International., 73, 3-12, 2015.

[2] N. Reddy, "Non- food industrial aplications of poultry feathers," Waste Management., 45, 91-107, 2015.

[3] G. Machuca Loja, B. Madrid Celi , D. Sanmartin Galvan y J. Pérez Rodríguez, Queratina a partir de la hidrólisis enzimática de harina de plumas de 
pollo, utilizando queratinasas producidas por Bacillus subtilis,UNEMI., 9, 50-58, 2016.

[4] DANE.Boletín Técnico del Producto Interno Bruto. Departamento Admirativo Nacional de Estadísticas, 2018.

[5] O.A. Ariza Andrade, Estudio de Impacto Ambiental para una Granja de Engorde en el Municipio de Fusagasugá. Disponible en: https://repository.unimilitar.edu.co/bitstream/handl e/10654/16439/ArizaAndradeOscarAlirio2017.pdf;j sessionid=C015AED343CDA61294BA7DBC6FB0 $5 A 8 F$ ?sequence $=1$ [Consultado el 30 de enero de 2019].

[6] T. Tesfaye, B. Sithole, D. Ramjugernath y V. Chunilall,.Valorisation of chicken feathers: Characterisation of physical properties and morphological structure. Journal of Cleaner Production., 149,349-365, 2017.

[7] M. V. Pérez Villa y R. A. Villegas Calle, Procedimientos para el manejo de residuos orgánicos avícolas.Universidad de Antioquia, 2009.

[8] C. R. Holkar, S. S. Jain, A. J. Jadhav y D. V. Pinjari. Valorization of keratin based waste. Process Safety and Environmental Protetion., 115, 85-98, 2018.

[9] M. V. S. Cedilo. Determinación de método para la obtención de queratina cosmética a partir de plumas gallináceas. Universidad Central del Ecuador, 2013.

[10] G. Morales Forqueras, A. F. Soria Tornazos, S. A. Salas Aguilar, M. Marca Lazarte, I. Cardozo y X. Huaniquina Terrazas. Obtención de fibras de queratina a partir de plumas de aves de corral para la elaboración de una crema para problemas capilares,2011. Disponible en: https://kupdf.net/download/perfil-obtencion-defibras-de-queratina-a-partir-de-plumas-de-avesde-corral-para-la-elaboracion-de-una-crema-paraproblemas-

capilares_5cd42b89e2b6f5d3706c4d4c_pdf

[11] J. M. Orjuela Palacio, M. C. Lanari Vila y N. E. Zaritzky, «Desarrollo de Productos a Base de Queratina a Partir de residuos de la Industria Avícola,» III Jornadas de Investigación, Transferencia y Extensión de la Facultad de Ingeniería, pp. 503-508, 2015.

[12] M. B. Valencia Andrade. Obtención de Queratina a partir de plumas de la Industria Avícola mediante Hidrólisis Enzimática. Universidad de las Américas, Quito, 2018.
[13] K. Chávez Marín. and C. Tenorio Hernández, Estudio para la obtención de queratina a partir de plumas de pollo con los métodos de sulfuro de sodio y borohidruro de sodio a nivel de laboratorio. Disponible en:http://ribuni.uni.edu.ni/1473/. [Consultado el 5 de abril del 2018].

[14] Fichas de seguridad de Sodio borohidruro. Disponible en: https://www.carlroth.com/downloads/sdb/es/4/SDB _4051_ES_ES.pdf.

[15] Fichas de datos de seguridad Sulfuro de Sodio.Disponibe en: http://solkem.com.ar/wpcontent/uploads/SULFURO-DE-SODIO-FDS.pdf.

[16] G. I. I. b. Nature, Ficha técnica Genencor® Tan G, 2004. Disponible en: http://merquiand.com/es/quimicoespecializado?id=73.

[17] G. J. Machuca Loja. Obtención de queratina a partir de plumas de pollo utilizando Queratinasas producidas por Bacillus spp. San Antonio de Machala, 2015.

[18] J. Hernandez Fernandez, L. Ramirez Reyes, N. Ramires Hernandez y L. S. Fuentes Quintero, «Caracterización Molecular,» de Métodos estandarizados para la caracterización de cepas nativas de Bacillus thuringiensis para el control de insectos plaga: modelo Tuta absoluta, Bogotá, Universidad de Bogotá Jorge Tadeo Lozano, 2012, pp. 31-38.

[19] H. Gutiérrez Pulido and R. Vara Salazar, Análisis y diseño de experimentos. México D.F.: McGraw-Hill, 2012.

[20] Applied Biological Materials nc., "Opti-Protein XL Marker,". Disponible en: https://www.abmgood.com/Protein-Marker-BioRad.html [Consultado el 14 de noviembre de 2018].

[21] E. Gaviria Acosta, R. Benítez y L. Lenis, "Optimización de la hidrólisis enzimática de proteínas presentes en semillas de guandul (Cajanus Cajan)," Biotecnología en el Sector Agropecuario y Agroindustrial., 13, 114-122, 2015.

[22] R. Benítez, A. Ibarz y J. Pagan. Hidrolizados de proteína: procesos y aplicaciones. Acta Bioquímica Clínica Latinoamericana., 42, 36-227, 2008. 